\title{
A preliminary analysis of the surface chemistry of atmospheric aerosol particles in a typical urban area of Beijing
}

\author{
Zhengzheng Zhang ${ }^{1,2}$, Hong $\mathrm{Li}^{2,3, *}$, Hongyan Liu ${ }^{1}$, Runxiang $\mathrm{Ni}^{4}$, Jinjuan $\mathrm{Li}^{1}$, Liqun Deng ${ }^{6}$, \\ Defeng $\mathrm{Lu}^{5}$, Xueli Cheng ${ }^{7}$, Pengli Duan ${ }^{8}$, Wenjun $\mathrm{Li}^{1,2}$
}

1. College of Resource and Environmental Engineering, Guizhou University, Guiyang 550025, China. E-mail: zanezz@yahoo.com

(Zhengzheng Zhang),

2. State Key Laboratory of Environmental Criteria and Risk Assessment, Chinese Research Academy of Environmental Sciences, Beijing 110012, China

3. Collaborative Innovation Center on Atmospheric Environment and Equipment Technology, Nanjing University of Information Science and Technology, Nanjing 210044, China

4. Institute of Geographic Sciences and Natural Resources Research, CAS, Beijing 100101, China

5. Core Tech Integrated (Beijing) Pty. Ltd., Beijing 100086, China

6. Sichuan Academy of Environmental Sciences, Sichuan 610041, China

7. SAE Technology Development (Dongguan) Co. Ltd., Guangdong 523087, China

8. Institute of Environment Science, Shaanxi University, Shaanxi 030006, China

\section{A R T I C L E I N F O}

Article history:

Received 19 September 2015

Revised 25 January 2016

Accepted 26 January 2016

Available online 19 April 2016

Keywords:

Atmospheric aerosol

Surface chemistry

Influential factors

TOF-SIMS

Beijing

\begin{abstract}
A B S T R A C T
Atmospheric aerosol particle samples were collected using an Ambient Eight Stage (Non-Viable) Cascade Impactor Sampler in a typical urban area of Beijing from 27th Sep. to 5th Oct., 2009. The surface chemistry of these aerosol particles was analyzed using Static Time of Flight-Secondary Ion Mass Spectrometry (Static TOF-SIMS). The factors influencing surface compositions were evaluated in conjunction with the air pollution levels, meteorological factors, and air mass transport for the sampling period. The results show that a variety of organic ion groups and inorganic ions/ion groups were accumulated on the surfaces of aerosol particles in urban areas of Beijing; and hydrophobic organic compounds with short- or middle-chain alkyl as well as hydrophilic secondary inorganic compounds were observed. All these compounds have the potential to affect the atmospheric behavior of urban aerosol particles. $\mathrm{PM}_{1.1-2.1}$ and $\mathrm{PM}_{3.3-4.7}$ had similar elements on their surfaces, but some molecules and ionic groups demonstrated differences in Time of Flight-Secondary Ion Mass Spectrometry spectra. This suggests that the quantities of elements varied between $\mathrm{PM}_{1.1-}$ 2.1 and $\mathrm{PM}_{3.3-4.7}$. In particular, more intense research efforts into fluoride pollution are required, because the fluorides on aerosol surfaces have the potential to harm human health. The levels of air pollution had the most significant influence on the surface compositions of aerosol particles in our study. Hence, heavier air pollution was associated with more complex surface compositions on aerosol particles. In addition, wind, rainfall, and air masses from the south also greatly influenced the surface compositions of these urban aerosol particles.

(c) 2016 The Research Center for Eco-Environmental Sciences, Chinese Academy of Sciences.
\end{abstract}

Published by Elsevier B.V.

\footnotetext{
* Corresponding author at: State Key Laboratory of Environmental Criteria and Risk Assessment, Chinese Research Academy of Environmental Sciences, Beijing 110012, China. E-mail: lihong@craes.org.cn (Hong Li).
} 


\section{Introduction}

Surface physicochemical processes determine material conversion (Rita et al., 2006), energy transfer, and chemical conversion on the surfaces of aerosol particles (Peterson et al., 2006; Chan et al., 1997). Such transformations in aerosol particles affect both the environment and human health (Wang et al., 2011; Tang et al., 2006; Wei et al., 2009). In the context of their close relationship to aerosol surface area, morphology, surface chemical composition, structure and other surface characteristics (Zhu et al., 2010; Lazzeri et al., 2003; Xu, 2006; Li et al., 2007; Li et al., 2010; Wu et al., 2009; Lu et al., 2013; Bluhm and Siegmann, 2009; Sobanska et al., 2014), study of the surface physicochemical characteristics of aerosol particles has become an important aspect of aerosol particle research.

The main techniques for surface chemical and imaging analysis include Scanning Electron-Energy Dispersive X-ray Spectrometry (SEM-EDX), Auger Electron Spectroscopy (AES), X-ray Photoelectron Spectroscopy (XPS or EDCA), Atomic Force Microscopy (AFM), and Time of Flight-Secondary Ion Mass Spectrometry (TOF-SIMS) (Li et al., 2015). Compared with other surface analysis techniques, TOF-SIMS can distinguish ions of elements with low atomic numbers $(Z<11, Z=$ atomic number) as well as their isotopes, with high sensitivity and fine transverse and depth resolution (such as lateral resolution $<50 \mathrm{~nm}$, depth resolution $<1 \mathrm{~nm}$, organic matters, monolayer $<10^{-6}$ ) (Benninghoven and Cha, 2002; Zhou et al., 2004). The technique has two working modes, which are Static TOF-SIMS and Dynamic TOF-SIMS. Static TOF-SIMS can be used for surface mass spectrometry and imaging; while Dynamic TOF-SIMS is mainly used for in-depth analysis (Benninghoven and Cha, 2002; Stephan, 2001). TOF-SIMS has been widely used in microelectronics, materials science, nanotechnology, life sciences, space technology, and environmental science (Suzuki et al., 2006; Ni et al., 2012; Li et al., 2015).

In recent years, TOF-SIMS has been applied to many aspects of aerosol science studies, such as surface chemical composition, depth analysis of surface chemical composition, surface chemical reaction, surface toxicity and characteristics and identification of aerosol particle sources. Peterson and Tyler (2002, 2003) studied the surface inorganic and organic composition of particles from a Montana forest fire and Hawaiian sea salt, and discussed their interaction by combining the technique of Static TOF-SIMS and other surface techniques, such as XRF and SEM-EDX. Tervahattu et al. (2002) analyzed the surface composition of oceanic aerosol particles by using both Static TOF-SIMS and Dynamic-TOF-SIMS, and found some evidence for the existence of a surfactant layer on the aerosol surface. Palma et al. (2007) obtained the surface depth profile and 3D imaging of aerosol particles by Dynamic TOF-SIMS. Rita et al. (2006) studied the chemical reaction process of aerosol particles by using Static TOF-SIMS. Tomiyasu et al. (2004) studied the surface composition of diesel engine exhaust particles and iron particles, and discussed their health effects by combining the techniques of Dynamic TOF-SIMS, FE-SEM and EPMA (Electron Probe Microanalysis). Mayama et al. (2012) analyzed the surface composition of aerosol particles and identified their sources by using Dynamic TOF-SIMS and EPMA. These works helped to improve our knowledge about the surface characteristics of aerosol particles and the mechanism of surface chemical reactions on the aerosol particles.

However, based on the available literature, the application of TOF-SIMS techniques in the field of aerosol science is rare in China so far. Yu et al. (2000) studied the PAHs on individual particles in Beijing and got some "fingerprints" for identification of particle sources. Liang et al. (2001) analyzed PAHs on individual particles and provided a rapid method for qualitative analysis of PAHs and oxygenated-PAHs on aerosol particles. Mei et al. (2002) resolved the surface organic components of aerosol particles stemming from tobacco smoke and found that these particles contained N-containing heterocyclic compounds and PAHs using TOF-SIMS. Li et al. (2010) analyzed the surface inorganic compositions of fine and coarse aerosol particles, and found that atmospheric secondary hydrophilic inorganic compounds were present on the aerosol particles using the static TOF-SIMS technique. These publications concern either inorganic components or organic structure, but not the identification of qualitative organic species on the surface of aerosol particles.

With the development of the economy and society, air pollution has become an important environmental issue in Beijing. Heavy haze events have occurred frequently in Beijing in recent years (Bai et al., 2006; Zhu et al., 2010; Wu, 2012), which may have had adverse effects on the exposed population. In order to develop effective air pollution control measures, it is important to clarify the formation mechanisms of aerosol particles in the ambient air of Beijing. Among these mechanisms, heterogeneous reaction processes and mechanisms are the least understood, due to the lack of knowledge on the surface chemical composition and structure of aerosol particles (Wu, 2012; He et al., 2013). Therefore, it is necessary to carry out studies on the characterization of the inorganic and organic composition and structure of aerosol particles in Beijing. In our study, the surface chemical composition of aerosol particles from a typical urban area of Beijing was measured using Static TOF-SIMS. We determined the compositional characteristics of fine and coarse mode aerosol particles and correlated these with levels of air pollution, meteorological factors, and air mass transport.

\section{Materials and experimental methods}

\subsection{Sample collection}

Aerosol samples were collected on the roof of the Atmospheric Research Building of the Chinese Research Academy of Environmental Sciences (CRAES) in the Chaoyang District, Beijing $\left(40^{\circ} 02^{\prime} \mathrm{N}, 116^{\circ} 25^{\prime} \mathrm{E}\right)$. The site is $15 \mathrm{~m}$ above the ground. It is in a residential and commercial area, adjacent to residential buildings to the east and north, $100 \mathrm{~m}$ from Chunhua Road to the south, and $450 \mathrm{~m}$ from Lishuiqiao South subway station to the west. There is no industrial pollution source within $500 \mathrm{~m}$ or any other notable local pollution source around the sampling site. It is representative of a typical urban area within Beijing.

The samples were collected using an Ambient Eight Stage (Non-Viable) Cascade Impactor Sampler (TISCH Environmental Inc., OH, USA), with aluminum substrates $(d=81 \mathrm{~mm})$ and glass fiber substrates ( $d=81 \mathrm{~mm}$, only used in layer $F$ ). It consists of 
nine successive stages (layers $0-F$ ), which corresponded to size segregations of $>9 \mu \mathrm{m}, 5.8-9 \mu \mathrm{m}, 4.7-5.8 \mu \mathrm{m}, 3.3-4.7 \mu \mathrm{m}$, 2.1-3.3 $\mu \mathrm{m}, 1.1-2.1 \mu \mathrm{m}, 0.65-1.1 \mu \mathrm{m}, 0.43-0.65 \mu \mathrm{m}$ and $\leq 0.43 \mu \mathrm{m}$, respectively. Sampling volume was calibrated using a set flow rate of $28.3 \mathrm{~L} / \mathrm{min}$ ( $\approx 1$ cubic foot per min). Relevant meteorological data for sampling dates, including temperature, humidity, wind speed, and wind direction are given in Table 1 (http:// simplifiedchinese.wunderground.com).

Sampling was carried out between 16:50-17:50 on 27th Sep., 2009; but over two intervals: 7:30-9:30 and 19:30-21:30 from 28th Sep. to 5th Oct., 2009. In total, 159 samples were collected. Ten samples of $\mathrm{PM}_{1.1-2.1}$ and ten samples of $\mathrm{PM}_{3.3-4.7}$ collected on aluminum substrates were selected for study using TOF-SIMS. Background information for these samples is given in Table 2.

Before sampling, the aluminum substrates were heated in a muffle furnace at $400^{\circ} \mathrm{C}$ for $4 \mathrm{hr}$; they were then cooled in a dryer. Before and after sampling, the aluminum substrates were kept in a chamber at $25^{\circ} \mathrm{C}$ with a humidity of $50 \%$ for $24 \mathrm{hr}$ Samples were weighed using an electronic scale with precision of 1/100,000 after sampling, and stored in a refrigerator before analyzing them.

\subsection{Experimental method and data analysis}

The samples were measured using a TOF-SIMS TRIFT II Model 2000 (Physical Electronics, MN, USA). This instrument comprises a vacuum chamber, air pump system, sample input and operation system, primary ion source, mass spectrometer, secondary ion detector, and data processing computer. Using a $\mathrm{Ga}^{+}$pulse $\left({ }^{69} \mathrm{Ga}\right)$, the peak width at half-height can reach $<700$ ps. It also includes an electronic gun to remove electronic charge in non-conductive samples. Its greatest advantages are its high resolution and ability to detect the element $\mathrm{H}(\mathrm{m} / \mathrm{z}=1)$, as well as other ions and ion groups. Its sample pre-processing chamber and instrument chamber are one-hundred-grade clean chambers that remove the potential for secondary pollution during pre-processing and measuring to improve the accuracy of the experimental results. Measurements were performed using the large area surface mass spectrometry mode of static TOF-SIMS, with a primary ion current of $2 \mathrm{nA}$, and an analysis period of $3 \mathrm{~min}$. During this time, the ion beam bombarded an area $100 \times 100 \mu \mathrm{m}^{2}$ (in the center of the sample), and an electronic gun was used to remove the charge effects. With the vacuum degree in the sample analysis chamber set at $10^{-8}$ Torr or below and one beam $\left({ }^{69} \mathrm{Ga}\right)$ of $15 \mathrm{keV}$, the mass

\section{Table 2 - General information for TOF-SIMS samples.}

\begin{tabular}{|c|c|c|c|}
\hline $\begin{array}{l}\text { Sample } \\
\text { number }\end{array}$ & $\begin{array}{l}\text { Sampling time } \\
\text { (mm/dd) }\end{array}$ & $\begin{array}{l}\text { Particle size } \\
(\mu \mathrm{m})\end{array}$ & $\begin{array}{l}\text { Measured } \\
\text { areas }^{\#}\end{array}$ \\
\hline 126 & 9/27 p.m. & $\mathrm{PM}_{1.1-2.1}$ & 2 \\
\hline 006 & 9/28 a.m. & $\mathrm{PM}_{1.1-2.1}$ & 2 \\
\hline 022 & 9/29 a.m. & $\mathrm{PM}_{1.1-2.1}$ & 2 \\
\hline 030 & 9/29 p.m. & $\mathrm{PM}_{1.1-2.1}$ & 2 \\
\hline 038 & 9/30 a.m. & $\mathrm{PM}_{1.1-2.1}$ & 2 \\
\hline 046 & 9/30 p.m. & $\mathrm{PM}_{1.1-2.1}$ & 2 \\
\hline 054 & 10/01 a.m. & $\mathrm{PM}_{1.1-2.1}$ & 2 \\
\hline 062 & 10/01 p.m. & $\mathrm{PM}_{1.1-2.1}$ & 2 \\
\hline 070 & 10/02 a.m. & $\mathrm{PM}_{1.1-2.1}$ & 2 \\
\hline 078 & 10/02 p.m. & $\mathrm{PM}_{1.1-2.1}$ & 2 \\
\hline 124 & 9/27 p.m. & $\mathrm{PM}_{3.3-4.7}$ & 2 \\
\hline 004 & 9/28 a.m. & $\mathrm{PM}_{3.3-4.7}$ & 2 \\
\hline 020 & 9/29 a.m. & $\mathrm{PM}_{3.3-4.7}$ & 2 \\
\hline 028 & 9/29 p.m. & $\mathrm{PM}_{3.3-4.7}$ & 2 \\
\hline 036 & 9/30 a.m. & $\mathrm{PM}_{3.3-4.7}$ & 2 \\
\hline 044 & 9/30 p.m. & $\mathrm{PM}_{3.3-4.7}$ & 2 \\
\hline 052 & 10/01 a.m. & $\mathrm{PM}_{3.3-4.7}$ & 2 \\
\hline 060 & 10/01 p.m. & $\mathrm{PM}_{3.3-4.7}$ & 2 \\
\hline 068 & 10/02 a.m. & $\mathrm{PM}_{3.3-4.7}$ & 2 \\
\hline 076 & 10/02 p.m. & $\mathrm{PM}_{3.3-4.7}$ & 2 \\
\hline Blank sample & - & - & 2 \\
\hline
\end{tabular}

resolution obtained was $m / \Delta m>9000\left({ }^{28} \mathrm{Si}\right)$. Positive and negative secondary ion modes were used.

As aluminum substrates with high electrical conductivity were used to collect aerosol samples in our study, ions and ion groups with large mass numbers were detected with static TOF-SIMS, using the electronic gun to disperse charge effects while ion beams were striking the sample surface. The samples were cut to the required size for the sample stage, put on a stainless steel shim, and placed into the equipment for analysis. Four samples were put on the sample stage at a time. Therefore, the samples were divided into five groups (Table 2): group 1 (No. 020, No. 022, No. 028 and No. 030), group 2 (No. 036, No. 038, No. 044 and No. 046), group 3 (No. 052, No. 054, No. 060 and No. 062), group 4 (No. 068, No. 070, No. 076 and No. 078), and group 5 (No. 004, No. 006, No. 124 and No. 126). Groups 1-4 were analyzed the same day, and group 5 and another two blank samples were measured the next day. To ensure the stability of the peaks obtained from TOF-SIMS, samples 004, 006, 124 and 126 were measured twice. The relative standard deviations of the normalized peaks obtained from the same samples ranged from $4 \%$ to $25 \%$.

Table 1 - Sampling time and weather conditions.

\begin{tabular}{|c|c|c|c|c|c|}
\hline Date & $\begin{array}{c}\text { Temperature } \\
\left({ }^{\circ} \mathrm{C}\right)\end{array}$ & $\begin{array}{l}\text { Relative humidity } \\
(\%)\end{array}$ & $\begin{array}{l}\text { Wind speed } \\
(\mathrm{m} / \mathrm{sec})\end{array}$ & Wind direction & Weather \\
\hline 2009-09-27 & 21 & 85 & 2.2 & No wind & Overcast \\
\hline 2009-09-28 & 21 & 65 & 1.8 & $\mathrm{SE}$ & Overcast \\
\hline 2009-09-29 & 19 & 89 & 1.8 & ESE & Moderate rain \\
\hline 2009-09-30 & 20 & 89 & 1.3 & No wind & Shower \\
\hline 2009-10-01 & 21 & 66 & 1.8 & $\mathrm{~N}$ & Moderate rain \\
\hline 2009-10-02 & 18 & 46 & 2.7 & SSW & Cloudy \\
\hline 2009-10-03 & 16 & 42 & 2.7 & $\mathrm{SE}$ & Cloudy \\
\hline 2009-10-04 & 16 & 46 & 2.7 & SSW & Sunny \\
\hline 2009-10-05 & 16 & 59 & 1.3 & No wind & Sunny \\
\hline
\end{tabular}


Organic and inorganic fragment ions can be distinguished based on their mass defects. Taking a zero carbon mass defect as the baseline, organic ions generally have a positive defect, while inorganic elements (with $Z>8$ ) have a negative defect. Therefore, based on the relationship of ion mass to theoretical element mass, we can identify the peaks in the spectra (Dai et al., 2000).

Twenty aerosol samples were analyzed using our mass spectrometric instrument and 84 spectra were obtained (42 spectra for the positive ion mode and 42 for the negative mode; blank samples included.). The peaks in the spectra are characteristic of the surface composition of the measured area of the aerosol sample. Peaks were normalized to assist with identification and facilitate comparison between samples. Since aluminum substrates were used in this study, the peak for $\mathrm{Al}^{+}$would be influenced by the background value; in addition, the peak for $\mathrm{Si}^{+}$was also strong in the blank samples. Therefore, the $\mathrm{Al}^{+}$and $\mathrm{Si}^{+}$ions were not evaluated in this study in order to avoid interference.

\section{Results and discussion}

\subsection{Classification of static TOF-SIMS peaks}

As seen in Fig. 1, there may be one or several fragment ions for each mass number for peaks in the spectra obtained with a static TOF-SIMS. Under the positive ion mode, 14 secondary ions were detected in the aerosol particle samples, while under the negative mode, 20 secondary ions were detected (Table 3).

In the aerosol particle samples, secondary ions and ion groups of elements with low and medium atomic weights (Fig. 1), such as $\mathrm{Li}^{+}, \mathrm{O}^{-}, \mathrm{F}^{-}, \mathrm{Na}^{+}, \mathrm{Mg}^{+}, \mathrm{Al}^{+}, \mathrm{Si}^{+}, \mathrm{NH}_{4}^{+}, \mathrm{C}_{3} \mathrm{H}_{3}^{+}, \mathrm{C}_{7} \mathrm{H}_{7}^{+}$, $\mathrm{C}_{2} \mathrm{H}^{-}, \mathrm{CN}^{-}, \mathrm{NO}_{2}^{-}, \mathrm{SO}^{-}, \mathrm{CNS}^{-}, \mathrm{SO}_{2}^{-}, \mathrm{SO}_{3}^{-}, \mathrm{NO}_{3}^{-}$and $\mathrm{HSO}_{4}^{-}$, were detected. In addition, secondary ion groups with large mass number, such as positive organic ion groups with mass to charge ratios of 73, 214, 219 and 239, and negative organic ion groups with mass to charge ratios of 203, 211, 239 and 255, were also detected, but not identified explicitly. Furthermore, there were peaks with large mass to charge ratios in the spectra, which indicate that some organic macromolecules or ion groups were created. During static TOF-SIMS, some molecular ions or ion groups might be induced from characteristic compounds on the surfaces of the samples, such as $\mathrm{H}_{2} \mathrm{SO}_{4}, \mathrm{NH}_{4} \mathrm{HSO}_{4},\left(\mathrm{NH}_{4}\right)_{2} \mathrm{SO}_{4}$, $\mathrm{NH}_{4} \mathrm{NO}_{3}, \mathrm{NH}_{4} \mathrm{Cl}, \mathrm{NaNO}_{3}$, and $\left(\mathrm{NH}_{4}\right)_{2} \mathrm{SO}_{4} \cdot \mathrm{MSO}_{4}$ ( $\mathrm{M}$ represents a metallic element) as well as short- or middle-chain organic alkyl compounds (like short- or middle-chain fatty acid compounds) (Tervahattu et al., 2002). Others are secondary compounds formed in the atmosphere, i.e., products of gases transforming to low volatile compounds (Harrison and Grieken, 1998; Peterson and Tyler, 2002). Therefore, the peaks of secondary ions demonstrate that there are compounds with these constituent ions on the surfaces of the samples, comprising secondary compounds formed in the atmosphere and organic compounds with alkyl groups. Both compound types influence the hydrophobic and hydrophilic surface characteristics of aerosol particles (Tervahattu et al., 2002; Richard and Bonnie, 2002), affecting the chemical behavior of these aerosol particles. Given the functional limitations of the instrument used in this study, not all of the secondary ions on the surface of aerosol particles were identified. Thus, a more comprehensive analysis of the surface compositions of aerosol particles will need to be carried out in future work.

\subsection{Characteristics of static TOF-SIMS peaks}

The characteristics of a static TOF-SIMS spectrum are relevant to establishing the surface compositions and atomic concentrations on the surfaces of the aerosol particles. They depend on the stability of the measured substances, the energy of the ion beam, the size of the ion group bombarded, and the yield of secondary ions. Therefore, the intensities of the static TOF-SIMS peaks can reflect the surface structure of the measured substances (Li et al., 2010; Rita et al., 2002; Dai et al., 2000).

The normalized secondary ion results for aerosol particles measured under the positive ion mode are shown in (Fig. 2). The results demonstrate that the positive ions on the surfaces of the aerosol particles collected in this study had similar peak intensities. $\mathrm{C}_{3} \mathrm{H}_{3}^{+}$had the strongest peak intensity, followed by $\mathrm{Mg}^{+}$, and then $\mathrm{Na}^{+}$and $\mathrm{NH}_{4}^{+}$. The peak intensities of $\mathrm{C}_{7} \mathrm{H}_{7}^{+}$and $\mathrm{Li}^{+}$were weak.

The peak intensities of secondary ions with mass to charge ratio larger than $200(\mathrm{~m} / \mathrm{z}=214,219,239)$ also were quite weak. On the surfaces of $\mathrm{PM}_{1.1-2.1}$ and $\mathrm{PM}_{3.3-4.7}, \mathrm{C}_{3} \mathrm{H}_{3}^{+}$and $\mathrm{C}_{7} \mathrm{H}_{7}^{+}$ accounted for a high proportion of peak intensities, although they were detected more frequently on the surfaces of $\mathrm{PM}_{3.3-4.7}$. The peak intensities of ions or ion groups with mass to charge ratio of 73 were also intense. The peak intensities of other secondary organic ion groups with larger mass to charge ratios were relatively weak. There were a number of interesting patterns observed for particular samples. The peak intensities of $\mathrm{C}_{3} \mathrm{H}_{3}^{+}$and $\mathrm{Mg}^{+}$on the surface of aerosol particles were strong. $\mathrm{Na}^{+}$was frequently found on the surface of the $\mathrm{PM}_{3.3-4.7}$, which indicates that a sodium salt is usually attached to the cluster of particles called Na-rich particles (Li et al., 2011). The reason for the strong peaks of $\mathrm{C}_{3} \mathrm{H}_{3}^{+}$might be that there were many organic compounds in the measured area of the samples. On the surfaces of samples 020,028, 060 and 062, the normalized concentrations of $\mathrm{Na}^{+}$were relatively high; although this ion was detected more frequently on the surfaces of $\mathrm{PM}_{3.3-4.7}$, suggesting there were many sodium compounds on the surfaces of sample particles. It was raining while these samples were collected, with high relative humidity, but weak wind (Table 1). Thus, sodium compounds in the atmosphere appear to accumulate on the surfaces of $\mathrm{PM}_{3.3-4.7}$ more easily when relative humidity is high.

Normalized static TOF-SIMS peak intensities for aerosol particle samples under the negative ion mode are shown in Fig. 3. These spectra demonstrate that negative ions on the surfaces of $\mathrm{PM}_{1.1-2.1}$ and $\mathrm{PM}_{3.3-4.7}$ had similar peak intensities for samples collected in this study. The peak intensities of $\mathrm{O}^{-}$ and $\mathrm{OH}^{-}$were strongest. Their intensities accounted for more than $85 \%$ of the total peak intensities of all secondary ions. However, because the peak intensities of $\mathrm{O}^{-}$and $\mathrm{OH}^{-}$on the surfaces of blank samples were also quite strong, they were clearly affected by artifacts and were not included in this study. We focused our analysis on the other 17 secondary ions analyzed. Among these ions, $\mathrm{C}_{2} \mathrm{H}^{-}$had the greatest peak 

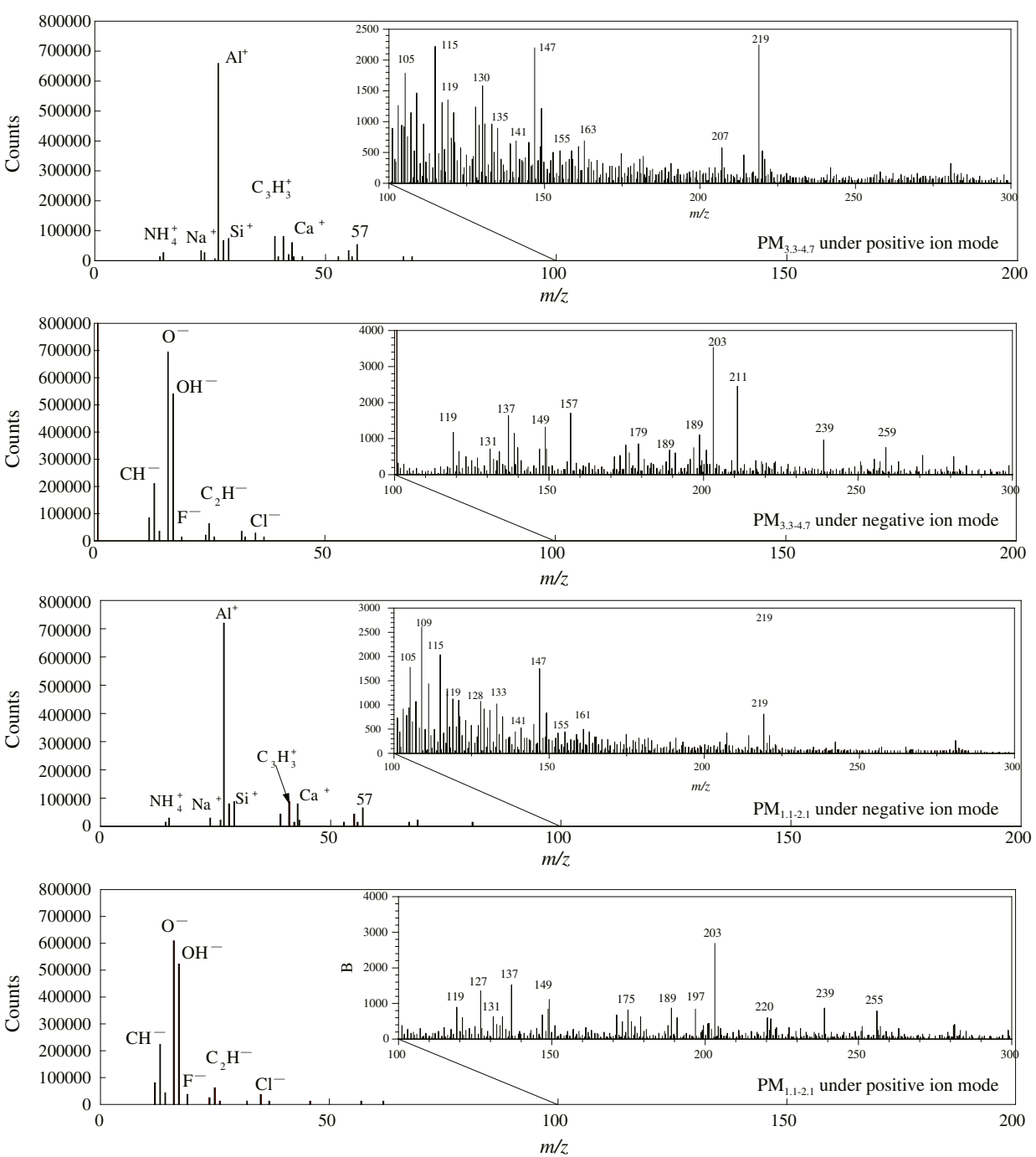

Fig. 1 - Typical static TOF-SIMS spectra for aerosol particle samples. TOF-SIMS: Time of Flight-Secondary Ion Mass Spectrometry.

Table 3 - Identification of static-TOF-SIMS ions in aerosol particle samples.

\begin{tabular}{|c|c|c|c|c|c|c|c|c|}
\hline \multicolumn{3}{|c|}{ Under positive ion mode } & \multicolumn{3}{|c|}{ Under negative ion mode } & \multicolumn{3}{|c|}{ Under negative ion mode } \\
\hline $\mathrm{m} / \mathrm{z}$ & Accurate value & Ion & $m / z$ & Accurate value & Ion & $m / z$ & Accurate value & Ion \\
\hline 7 & 7.02 & $\mathrm{Li}^{+}$ & 16 & 15.99 & $\mathrm{O}^{-}$ & 97 & 96.96 & $\mathrm{HSO}_{3}^{-}$ \\
\hline 18 & 18.04 & $\mathrm{NH}_{4}^{+}$ & 17 & 17 & $\mathrm{OH}^{-}$ & 203 & - & - \\
\hline 23 & 22.99 & $\mathrm{Na}^{+}$ & 19 & 19 & $\mathrm{~F}^{-}$ & 211 & - & - \\
\hline 24 & 38.96 & $\mathrm{Mg}^{+}$ & 25 & 25.01 & $\mathrm{C}_{2} \mathrm{H}^{-}$ & 221 & - & - \\
\hline 27 & 26.98 & $\mathrm{Al}^{+}$ & 26 & 26.01 & $\mathrm{CN}^{-}$ & 239 & - & - \\
\hline 28 & 27.98 & $\mathrm{Si}^{+}$ & 32 & 31.99 & $\mathrm{O}_{2}^{-}$ & 255 & - & - \\
\hline 39 & 38.96 & $\mathrm{~K}^{+}$ & 32 & 31.79 & $\mathrm{~S}^{-}$ & & & \\
\hline 39 & 39.02 & $\mathrm{C}_{3} \mathrm{H}_{3}^{+}$ & 35 & 34.79 & $\mathrm{Cl}^{-}$ & & & \\
\hline 40 & 39.96 & $\mathrm{Ca}^{+}$ & 46 & 45.99 & $\mathrm{NO}_{2}^{-}$ & & & \\
\hline 73 & - & - & 48 & 47.97 & $\mathrm{SO}^{-}$ & & & \\
\hline 91 & 91.05 & $\mathrm{C}_{7} \mathrm{H}_{7}^{+}$ & 58 & 57.98 & $\mathrm{CNS}^{-}$ & & & \\
\hline 214 & - & - & 60 & 59.97 & $\mathrm{SO}_{2}^{-}$ & & & \\
\hline 219 & - & - & 64 & 63.96 & $\mathrm{NO}_{3}^{-}$ & & & \\
\hline 239 & - & - & 80 & 79.96 & $\mathrm{SO}_{3}^{-}$ & & & \\
\hline
\end{tabular}



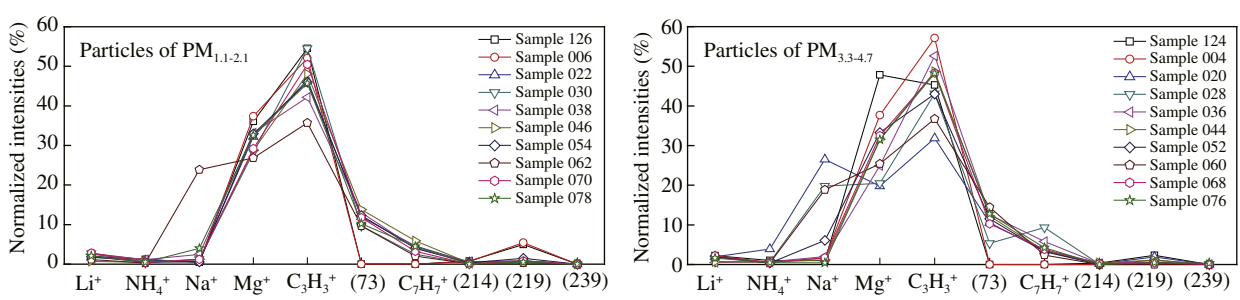

Fig. 2 - Normalized peak intensities of aerosol particle samples under positive ion mode. (73) represents ions or ion groups with mass to charge ratio of 73 ; similar for other mass values herein.

intensity, followed by $\mathrm{Cl}^{-}, \mathrm{F}^{-}$and $\mathrm{S}^{-}$, and then mass to charge ratio of $203, \mathrm{CN}^{-}, \mathrm{O}_{2}^{-}, \mathrm{NO}_{2}^{-}$and $\mathrm{SO}_{3}^{-}$. In contrast, the peak intensities of $\mathrm{SO}^{-}, \mathrm{CNS}^{-}, \mathrm{SiO}_{2}^{-}, \mathrm{SO}_{2}^{-}, \mathrm{HSO}_{4}^{-}$and mass to charge ratios of 203, 211, 221, 239 and 255 were relatively weak.

Under the positive ion mode, the surface compositions of $\mathrm{PM}_{1.1-2.1}$ and $\mathrm{PM}_{3.3-4.7}$ sampled at the same time were distinct (Fig. 4). Taking the samples collected in the morning of 29th Sep. as an example, the peak intensity of $\mathrm{C}_{3} \mathrm{H}_{3}^{+}$was strong on the surface of $\mathrm{PM}_{1.1-2.1}$, but somewhat weak on the surfaces of $\mathrm{PM}_{3.3-4.7}$; while the peak intensities of $\mathrm{Na}^{+}$and $\mathrm{NH}_{4}^{+}$were weak for $\mathrm{PM}_{1.1-2.1}$, but strong for $\mathrm{PM}_{3.3-4.7}$. The peak intensities of organic ion groups with mass to charge ratio of 219 were strong on the surface of $\mathrm{PM}_{1.1-2.1}$ collected on 27th and 28th Sep. (Fig. 4), but there were only weak or no peaks for these ion groups in samples collected at other times.

The surface compositions of samples collected at the same time on different days also varied. The normalized intensities of secondary ions changed with the day. The peak intensities of $\mathrm{C}_{3} \mathrm{H}_{3}^{+}$were strong on the surface of particle samples, and $\mathrm{C}_{7} \mathrm{H}_{7}{ }^{+}$ varied in response to the ionic strength of the particles' surface, which suggests that organic compounds with alkyl groups typically occur on the surface of these particles. This indicates that there were many long-chain hydrocarbons (Aliphatic hydrocarbons) (Cheng et al., 2014) on the surfaces of these samples, with $\mathrm{C}_{7} \mathrm{H}_{7}^{+}$ions likely derived from toluene-containing substances (Zhu et al., 2001). The peak intensity of $\mathrm{Na}^{+}$on the surface of $\mathrm{PM}_{1.1-2.1}$ and $\mathrm{PM}_{3.3-4.7}$ collected on 29th Sep. and 1st Oct. was expressed strongly, but there were only weak or no peaks for this ion in samples collected at other times. As shown in Table 1, there were moderate rains on 29th Sep. and 1st Oct. during the sampling period. Although there was also a shower on 30th Sep., the samplings were carried out during the periods without rain in that day, and no strong peaks of $\mathrm{Na}^{+}$were found in the samples collected on 30th Sep., either. Thus, we can deduce that the relatively high concentration of $\mathrm{Na}^{+}$on the surface of aerosol samples on 29th Sep. and 1st Oct. mainly came from the rain, and further studies will be carried out to find more evidence to support this assumption.

The characteristics of the surface compositions of $\mathrm{PM}_{1.1-2.1}$ and $\mathrm{PM}_{3.3-4.7}$ measured under the negative ion mode are shown in Fig. 5. Clearly, many secondary ions on the surfaces of aerosol particle samples were detected, but their peak intensities varied with particle size and sampling date. Comparing the aerosol particle samples collected before and after 28th Sep., the peak intensity of $\mathrm{CN}^{-}$(Rita et al., 2006; Zhu et al., 2001; Palma et al., 2007; Cheng et al., 2014) varied markedly: in fact, the initial strong signal was lost in the samples collected after 28th Sep. This suggests that samples collected after 28th Sep. had very low or no organic compounds containing $\mathrm{CN}^{-}$. We also detected $\mathrm{CNS}^{-}$in our study. These ions may be derived from nitrogen-containing organic compounds, just as $\mathrm{CN}^{-}$is derived from nitrile compounds (Zhu et al., 2001). There was no obvious change in the peak intensities of $\mathrm{F}^{-}$and $\mathrm{C}_{2} \mathrm{H}^{-}$, but the intensities of $\mathrm{Cl}^{-}$and $\mathrm{S}^{-}$ varied markedly. In addition, we see that the normalized intensities of peaks of negative ions on the surfaces of samples collected from the morning of 29th Sep. to the night of 30th Sep.
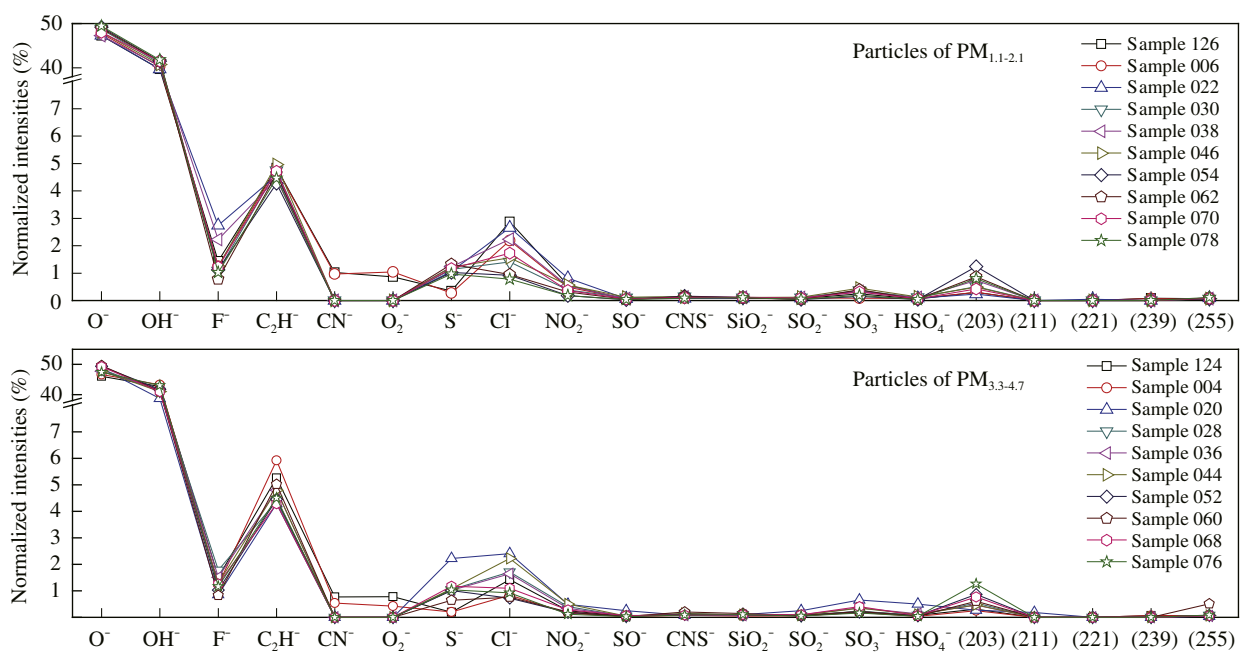

Fig. 3 - Normalized peak intensities of aerosol particle samples under negative ion mode. 

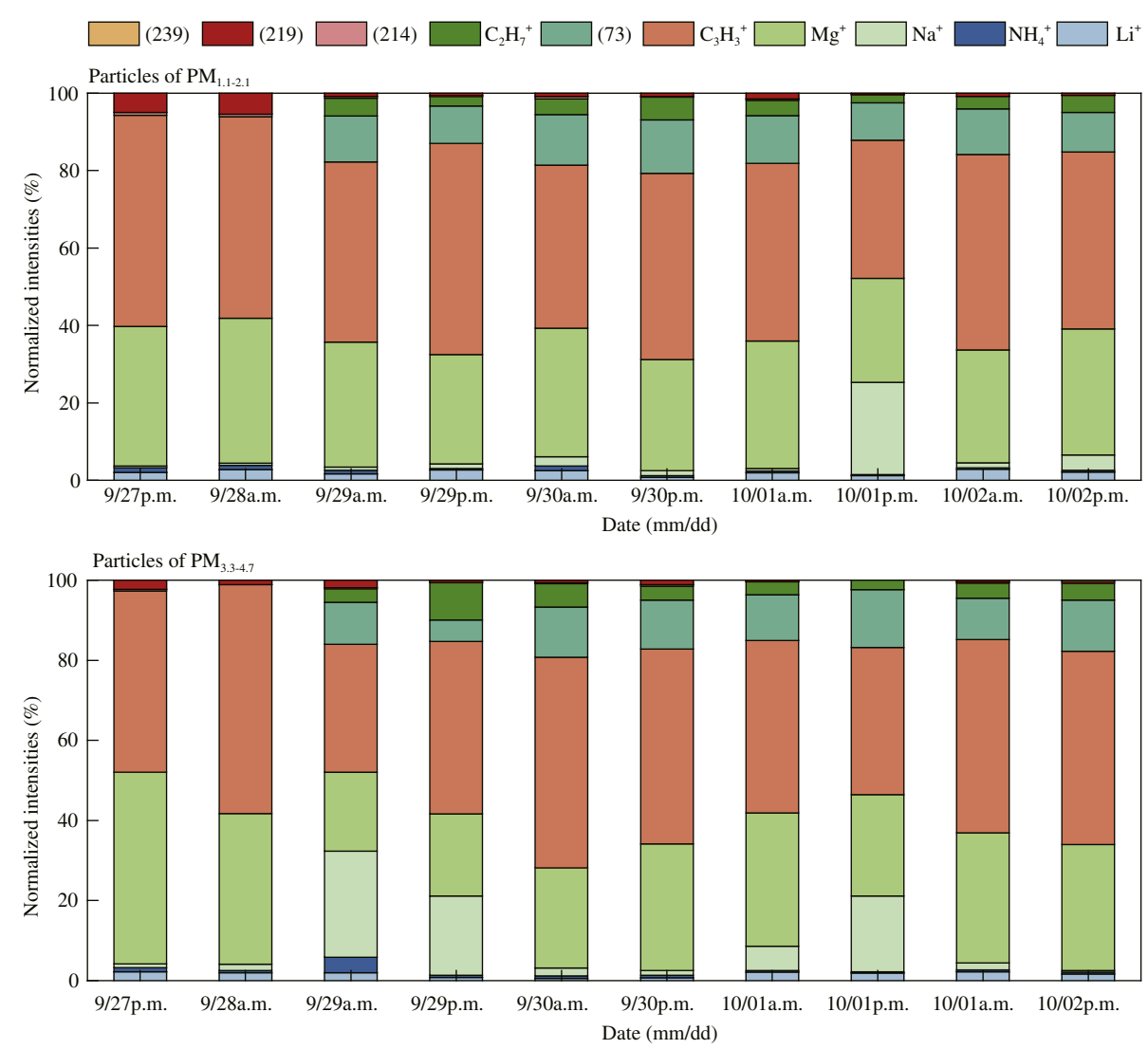

Fig. 4 - Comparison of the surface compositions of $\mathrm{PM}_{1.1-2.1}$ and $\mathrm{PM}_{3.3-4.7}$ under positive ion mode.

were high (Fig. 5). This indicates that there were more compounds on the surfaces of aerosols during this period. The peak intensities of $\mathrm{F}^{-}$were strong on the surfaces of both $\mathrm{PM}_{1.1-2.1}$ and
$\mathrm{PM}_{3.3-4.7}$. The higher the level of $\mathrm{PM}_{10}$ (the mass concentrations of $\mathrm{PM}_{10}$ were $143 \mu \mathrm{g} / \mathrm{m}^{3}$ and $173 \mu \mathrm{g} / \mathrm{m}^{3}$ on 29th and 30th Sep., with low wind speed and high relative humidity), the stronger the

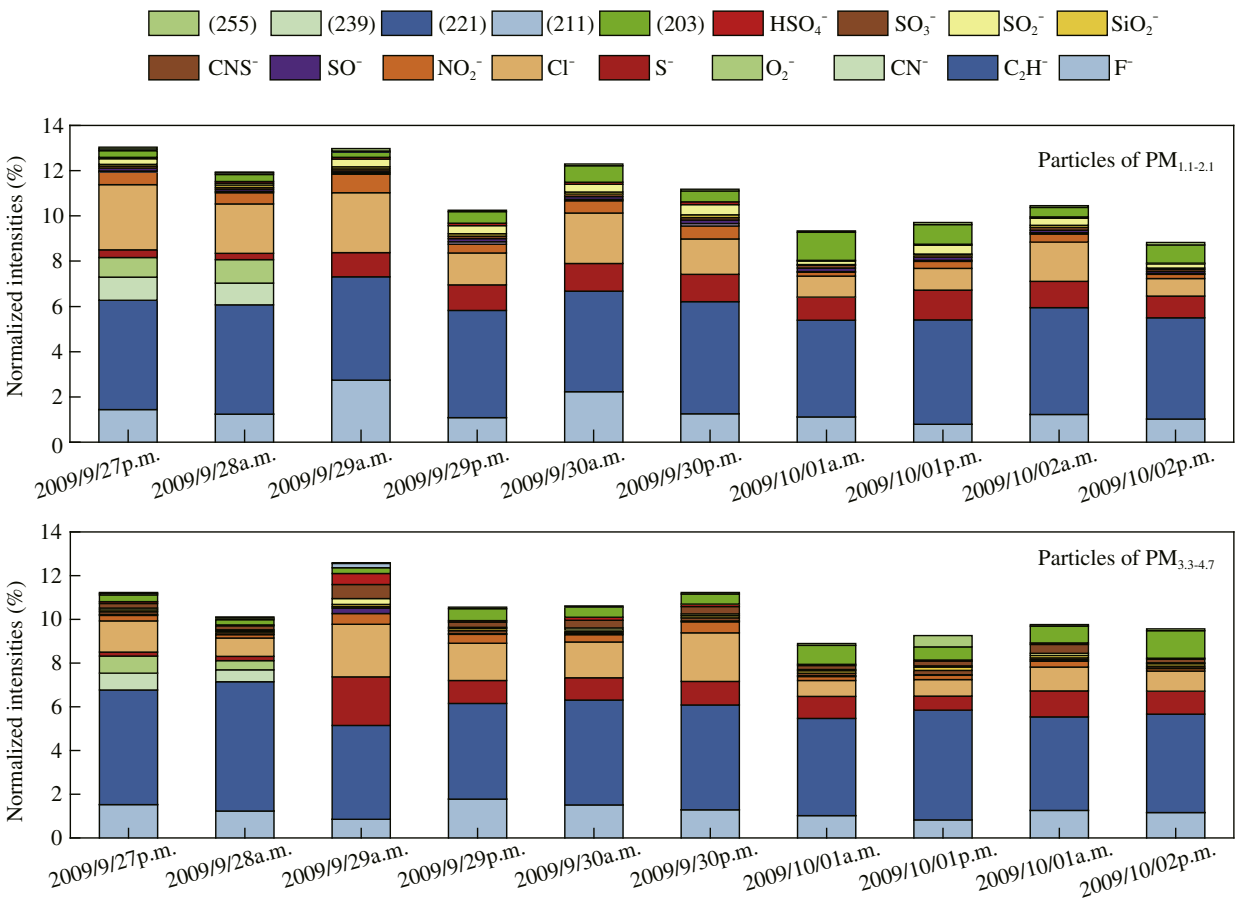

Fig. 5 - Comparison of the surface compositions of $\mathrm{PM}_{1.1-2.1}$ and $\mathrm{PM}_{3.3-4.7}$ under negative ion mode. 
peak intensity of $\mathrm{F}^{-}$on the surfaces of samples. Thus, we confirmed that fluorides exist on the surfaces of aerosol particles in urban Beijing (Li et al., 2010; Liang et al., 2001). This implies that some special pollution sources, such as fluoride-containing gases released from building materials, must be influencing the inorganic chemical compositions on the surfaces of aerosols (Liang et al., 2001).

Notably, fluoride can exist in gaseous or particle form in the atmosphere (GB 3095-2012). Both Rita et al. (2002, 2006) and Li et al. (2010) detected $\mathrm{F}^{-}$on the surface of urban aerosols. Studies have shown that excess ingestion of fluoride can cause fluorosis of the bones (Choubisa, 2012), digestive system (Suh et al., 2012), genitourinary system (Zhou et al., 2013; Kodama et al., 2010), nervous system (Luo et al., 2012; Xu and Xie, 2013), endocrine system (Sun et al., 2011; Al-Raddadi et al., 2012; Hou et al., 2013) and immune system (Xu et al., 2014) of animals to varying degrees. As $\mathrm{PM}_{1.1-2.1}$ are able to enter human bodies, fluorides on the aerosol surfaces may cause harm to human health; hence, more attention should be paid to controlling fluoride pollution in urban environments.

\subsection{Ambient factors influencing static TOF-SIMS peaks}

From 26th Sep. to 5th Oct., 2009, the mass concentrations of $\mathrm{PM}_{10}$ of Beijing increased at first, then decreased, and then increased again (Fig. 6). The mass concentration of $\mathrm{PM}_{10}$ reached its maximum $\left(173 \mu \mathrm{g} / \mathrm{m}^{3}\right)$ on 30th Sep. (http://www. bjmemc.com.cn/). During the sampling time, the wind speed decreased at first, then increased, and then decreased. It reached its minimum speed on 30th Sep. The weather reports indicate that slight haze pollution occurred in Beijing during this period (CMA, 2010).

We carried out 24-hr backward trajectory simulations on air masses from 28th Sep. to 2nd Oct., 2009, using the backward trajectory mode of HYSPLIT-4 and meteorological data from the global data assimilation system (GDAS) with an interval of $6 \mathrm{hr}$. We calculated 20 air mass transport trajectories for these 5 days. Fig. 7 shows that air masses were from the southeast, south, and southwest areas of Beijing (i.e., from Tianjin, Hebei, Shanxi and local areas around Beijing) from 28th to 30th Sep. Because the Beijing-Tianjin-Hebei region is densely populated, traffic on the main roads grew significantly with the approach of the National holiday; hence, vehicle exhaust emissions and dusts were likely sources of compounds in these air masses (Yuan et al., 2009; Lei et al., 2015). As wind weakened over the sampling period, pollutants accumulated in the air over Beijing, creating air pollution.

Meanwhile, the peak intensities of the 17 negative ions on the surfaces of the samples collected from 27th to 30th Sep. were obviously stronger than those in the samples collected on 1st and 2nd Oct., when the mass concentrations of $\mathrm{PM}_{10}$ were lower. Peaks of $\mathrm{CN}^{-}$and $\mathrm{O}_{2}^{-}$were detected in the samples collected on 27th and 28th Sep. when the mass concentrations of $\mathrm{PM}_{10}$ were relatively higher, but were not detected in those samples collected on other days, inferring that more species would be detected on the surface of aerosol particles with higher mass concentration of $\mathrm{PM}_{10}$. Peaks of $\mathrm{CN}^{-}$and $\mathrm{O}_{2}^{-}$were detected in the samples collected on 27th and 28th Sep. when the mass concentrations of $\mathrm{PM}_{10}$ were relatively higher, but were not detected in those samples collected on other days, inferring that more chemical species exist on the surface of aerosol particles with higher mass concentration of $\mathrm{PM}_{10}$. Peak intensities of $\mathrm{Li}^{+}, \mathrm{NH}_{4}^{+}, \mathrm{Na}^{+}, \mathrm{C}_{3} \mathrm{H}_{3}^{+}, \mathrm{C}_{7} \mathrm{H}_{7}^{+}, \mathrm{F}^{-}, \mathrm{C}_{2} \mathrm{H}^{-}, \mathrm{CN}^{-}, \mathrm{S}^{-}$, $\mathrm{Cl}^{-}, \mathrm{NO}_{2}^{-}, \mathrm{SO}^{-}, \mathrm{CNS}^{-}, \mathrm{SO}_{2}^{-}, \mathrm{SO}_{3}^{-}, \mathrm{HSO}_{4}^{-}$and ion groups with mass-to-charge ratios of 73, 214, 255 showed evident differences in samples collected on 29th and 30th Sep., compared with the samples collected on other days during the sampling period, and the normalized values of $\mathrm{NH}_{4}^{+}, \mathrm{C}_{3} \mathrm{H}_{3}^{+}, \mathrm{C}_{7} \mathrm{H}_{7}^{+}, \mathrm{F}^{-}, \mathrm{S}^{-}, \mathrm{Cl}^{-}$, $\mathrm{NO}_{2}^{-}, \mathrm{SO}^{-}, \mathrm{CNS}^{-}, \mathrm{SO}_{3}^{-}, \mathrm{HSO}_{4}^{-}$and ionic groups with mass-to-charge ratio of 73, 214 were higher in samples collected on 29th and 30th Sep. than those in samples collected on 1st and 2nd Oct. According to Pearson Correlation analysis, the coefficients between the mass concentrations of $\mathrm{PM}_{10}$ and the positive ions $\left(\mathrm{NH}_{4}^{+}, \mathrm{Na}^{+}\right.$, $\mathrm{C}_{7} \mathrm{H}_{7}^{+}$, ion groups with mass-to-charge ratios of 73,214$)\left(r_{\text {positive ion }}\right)$ are 0.14-0.37, while the coefficients between the mass concentrations of $\mathrm{PM}_{10}$ and the negative ions $\left(\mathrm{F}^{-}, \mathrm{S}^{-}, \mathrm{Cl}^{-}, \mathrm{NO}_{2}^{-}, \mathrm{SO}^{-}, \mathrm{CNS}^{-}\right.$, $\left.\mathrm{SO}_{2}^{-}, \mathrm{SO}_{3}^{-}, \mathrm{HSO}_{4}^{-}\right)\left(r_{\text {negative ion }}\right)$ are $0.19-0.61$. Since the correlation coefficients are all positive, this indicates that the higher the mass concentrations of $\mathrm{PM}_{10}$, the higher the concentrations of chemical substances on the surface of $\mathrm{PM}_{10}$. As a consequence,
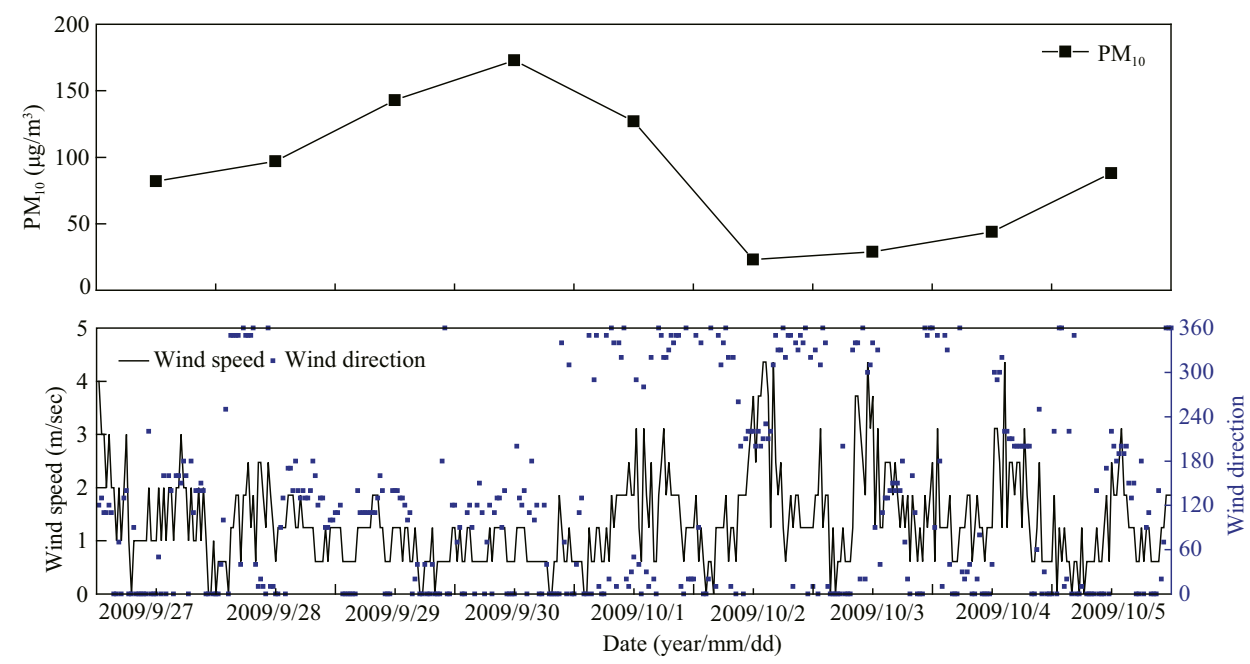

Fig. 6 - Relationship of $\mathrm{PM}_{10}$ and wind speed during the observation period. 


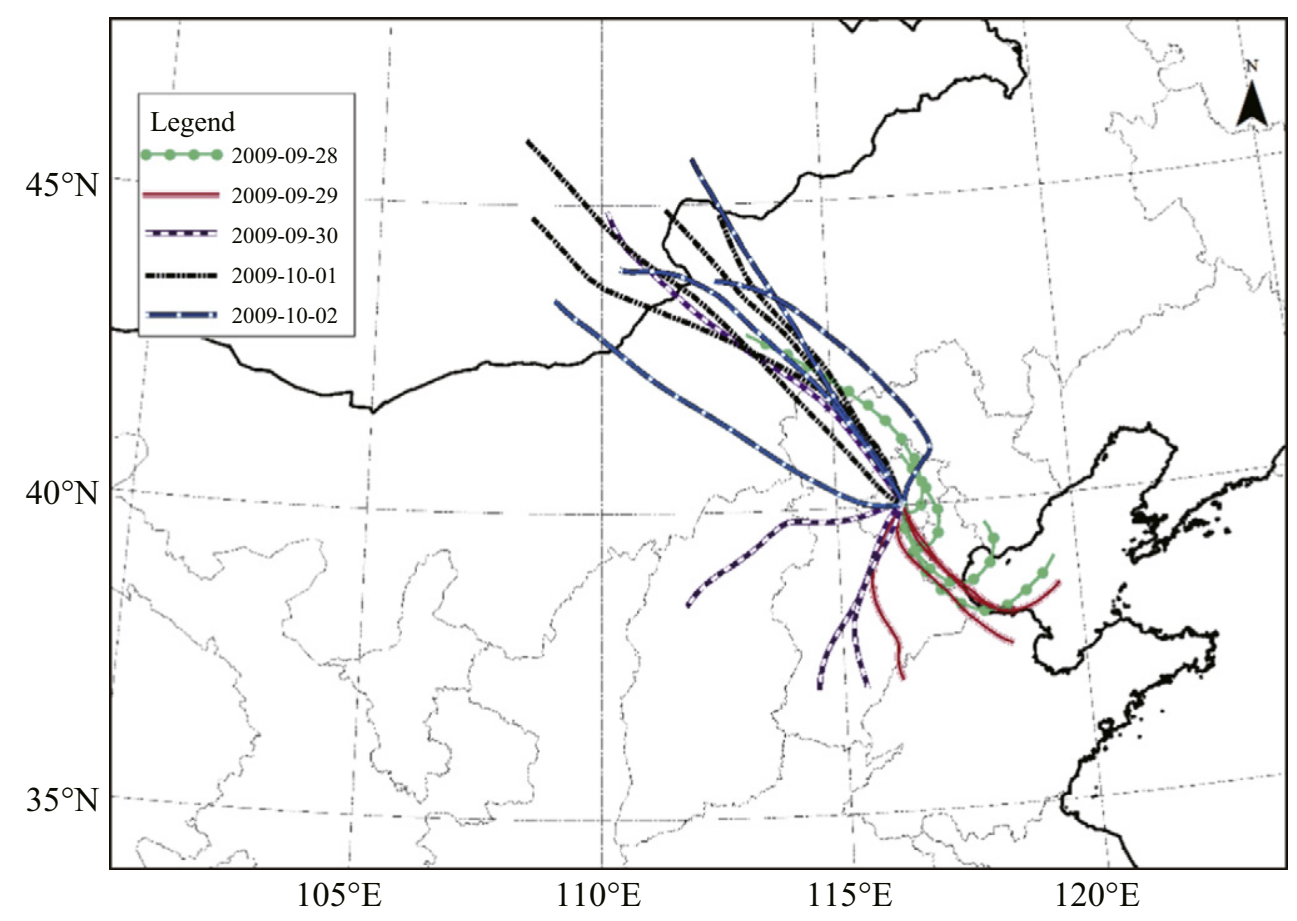

Fig. 7 - Backward trajectory simulation during the observation period.

the surface compositions of the aerosol particles became more complex, and concentrations of particular components on the aerosol particles increased. From 30th Sep. to 2nd Oct., the pollutants in the air were blown away by a northwesterly wind, and the traffic decreased. Therefore, the air quality improved, and the peak intensities of secondary ions on the surfaces of aerosol particles in the later period of the study were weaker.

Thus, the surface composition of aerosol particles is largely influenced by air pollution and also affected by meteorological factors, as well as air mass transport. Wind, rainfall and air mass from the southerly direction also had impacts on the surface chemistry of atmospheric aerosol particles.

\section{Conclusions}

Using static TOF-SIMS to analyze aerosol surfaces on aerosol particles collected within urban Beijing, we found that (1) $\mathrm{PM}_{1.1-2.1}$ and $\mathrm{PM}_{3.3-4.7}$ had similar surface chemistries, but the concentrations of some ions and ionic groups were quite distinct between $\mathrm{PM}_{1.1-2.1}$ and $\mathrm{PM}_{3.3-4.7}$. (2) Secondary inorganic compounds (such as $\mathrm{NH}_{4} \mathrm{HSO}_{4}$ and $\mathrm{NH}_{4} \mathrm{NO}_{3}$ ), organic alkyl compounds (like aliphatic compounds), and nitrogen-containing organic compounds occurred on the surfaces of these aerosol particles. Fluorides also were detected on their surfaces, suggesting that more attention must be paid to controlling fluoride pollution in urban environments. (3) The surface compositions of aerosol particles were clearly influenced by air pollution levels; the heavier the air pollution, the more complex were the surface chemical compositions of aerosol particles. Wind, rainfall, and air mass transport from the south also affected the surface compositions of atmospheric aerosol particles in urban Beijing.

\section{Acknowledgments}

This work was supported by the Project of National Natural Science Foundation of China (Nos. 41175111, 20677054, 21177078) and the Strategic Pilot Science and Technology Project of the Chinese Academy of Sciences (Class B) (No. XDB05010200). We would like to thank Miss Du Xiao-hui from Shandong Normal University and Mr. Meng Ling-shuo from the Guilin University of Technology for their help with the figures. We would also like to express our deep gratitude to the two anonymous reviewers for their valuable comments.

\section{R E F E R E N C E S}

Al-Raddadi, R.M., Bahijri, S.M., Al-Khateeb, T., 2012. 1026 excessive fluoride intake is associated with hyperparathyroidism and hypothyroidism in children and adolescent, Jeddah — Saudi Arabia. Arch. Dis. Child. 97 (Suppl. 2), A294.

Bai, Z.P., Cai, B.B., Dong, H.Y., Bian, H., 2006. Adverse health effects caused by dust haze-A review. Environ. Pollut. Control. 28 (3), 198-201.

Benninghoven, A., Cha, L.Z., 2002. TOF-SIMS - A powerful tool for practical surface, interface and thin film analysis. Vacuum 5 , 1-10.

Bluhm, H., Siegmann, H.C., 2009. Surface science with aerosols. Surf. Sci. 603 (10), 1969-1978.

Chan, Y.C., Simpson, R.W., Mctainsh, G.H., Vowles, P.D., Cohen, D.D., Bailey, G.M., 1997. Characterisation of chemical species in pm 2.5 and pm 10 aerosols in Brisbane, Australia. Atmos. Environ. 31 (22), 3773-3785.

Cheng, W., Weng, L.T., Li, Y., Lau, A., Chan, C., Chan, C.M., 2014. Characterization of size-segregated aerosols using TOF-SIMS 
imaging and depth profiling. Surf. Interface Anal. 46 (7), 480-488.

Choubisa, S.L., 2012. Status of fluorosis in animals. Proc. Natl. Acad. Sci. India 82 (3), 331-339.

CMA (China Meteorological Administration), 2010. Observation and forecasting levels of haze (QX/T 113-2010). Available at: http://www.cmastd.cn/standardRecordSearch_6.jspx.

Dai, S.F., Tang, Y.G., Yang, J.Y., Zhou, Q., Ai, T.J., 2000. Study of TOF-SIMS on hydrocarbon-generating potential of source rocks. J. China U. Min. Technol. 29 (6), 581-586.

Harrison, R.M., Grieken, R.V., 1998. IUPAC series on analytical and physical chemistry of environmental system. Wiley, Atmos. Part. New York.

He, H., Wang, X.M., Wang, Y.S., Wang, Z.F., Liu, J.G., Chen, Y.F., 2013. Formation mechanism and control strategies of haze in China. Bull. Chin. Acad. Sci. 28 (3), 344-352.

Hou, J.X., Yang, Y.J., Gong, B., Li, S.H., Ding, Z., Wen, S.B., et al., 2013. The influence of high fluoride exposure in drinking water on endocrine hormone in female. Chin. J. Prev. Med. 47 (2), 142-146.

Kodama, Y., Sugita-Konishi, Y., Aizawa, Y., 2010. Deterioration of renal function in ICR-derived glomerulonephritis (ICGN) mice by subacute administration of fluoride in drinking water. Fluoride 43 (1), 31-44.

Lazzeri, P., Clauser, G., Iacob, E., Lui, A., Tonidandel, G., Anderle, M., 2003. TOF-SIMS and XPS characterization of urban aerosols for pollution studies. Appl. Surf. Sci. 203, 767-771.

Lei, Y., Zhang, X.L., Tang, Y.X., Fan, G.Z., Zhou, D.W., 2015. Holiday effects on $\mathrm{PM}_{2.5}$ and other major pollutants in Beijing. Acta Sci. Circumst. 35 (5), 1520-1528.

Li, H., Chai, F.H., Lu, D.F., Wang, X.Z., Deng, L.Q., Ni, R.X., et al., 2010. Analysis of inorganic species on the surface of atmospheric aerosols collected in Beijing using time-of-flight static-secondary ion mass spectrometry. Res. Environ. Sci. 23 (5), 615-626.

Li, L., Chen, Z.M., Zhang, Y.H., Zhu, T., Li, S., Li, H.J., et al., 2007. Heterogeneous oxidation of sulfur dioxide by ozone on the surface of sodium chloride and its mixtures with other components. J. Geophys. Res. Atmos. (1984-2012). 112 (D18).

Li, W.J., Shao, L.Y., Shen, R.R., Yang, S.S., Wang, Z.S., Tang, U., 2011. Internally mixed sea salt, soot, and sulfates at Macao: A coastal city in South China. J. Air Waste Manage. Assoc. 61 (11), 1166-1173.

Li, W.J., Shao, L.Y., Zhang, D., Ro, C.U., Hu, M., Bi, X., et al., 2015. A review of single aerosol particle studies in the atmosphere of East Asia: Morphology, mixing state, source, and heterogeneous reactions. J. Clean. Prod. 112, 1330-1349.

Liang, H.D., Yu, C.H., Zhou, Q., Li, Y.F., 2001. TOF-SIMS study on PAHs in individual particle from a power station. J. China U. Min. Technol. (2), 150-154.

Lu, C., Zheng, X.M., Zhou, L.M., Yang, H.J., Chen, P.J., 2013. Measurements and characteristics of semiquinone radicals in urban atmospheric particles. Environ. Chem. 32 (1), 1-6.

Luo, Q., Cui, H.M., Peng, X., Fang, J., Zuo, Z.C., Liu, J., et al., 2012. Intestinal oxidative stress in broilers caused by high dietary fluorine. Fluoride 45 (4), 349-356.

Mayama, N., Goto, E., Miura, Y., Ohishi, K., Sakamoto, T., Takami, A., et al., 2012. Development of source apportionment of individual particle by high resolution time-of-flight secondary ion mass spectrometry. J. Vac. Soc. Jap. 55 (3), 104-107.

Mei, Z.Y., Yu, C.H., Liang, H.D., 2002. Secondary ion mass spectrometry analysis of cigarette smoke particles. J. Mass Spectrom. 15 (1), 30-34.

Ni, R.X., Li, H., Lun, X.X., Wen, C., 2012. Application advance review on the time-of-flight secondary ion mass spectrometry in the field of atmospheric aerosol. J. Saf. Environ. 116-122.

Palma, C.F., Evans, G.J., Sodhi, R.N., 2007. Imaging of aerosols using time of flight secondary ion mass spectrometry. Appl. Surf. Sci. 253 (14), 5951-5956.
Peterson, R.E., Tyler, B.J., 2002. Analysis of organic and inorganic species on the surface of atmospheric aerosol using time-of-flight secondary ion mass spectrometry (TOF-SIMS). Atmos. Environ. 36 (39), 6041-6049.

Peterson, R.E., Tyler, B.J., 2003. Surface composition of atmospheric aerosol: individual particle characterization by TOF-SIMS. Appl. Surf. Sci. 203, 751-756.

Peterson, R.E., Nair, A., Dambach, S., Arlinghaus, H.F., Tyler, B.J., 2006. Characterization of individual atmospheric aerosol particles with SIMS and laser-SNMS. Appl. Surf. Sci. 252 (19), 7006-7009.

Rita, V.H., Adriaens, A., Van Vaeck, L., Adams, F., 2006. The use of time-of-flight static secondary ion mass spectrometry imaging for the molecular characterization of single aerosol surfaces. Anal. Chim. Acta 558 (1), 115-124.

Rita, V.H., Annemie, A., Paolo, P., Alessandro, Z., Luc, V.V., Freddy, A., 2002. Static secondary ion mass spectrometry as a new analytical tool for measuring atmospheric particles on insulating substrates. Atmos. Environ. 36 (5), 899-909.

Sobanska, S., Falgayrac, G., Rimetz-Planchon, J., Perdrix, E., Brémard, C., Barbillat, J., 2014. Resolving the internal structure of individual atmospheric aerosol particle by the combination of atomic force microscopy, ESEM-EDX, Raman and TOF-SIMS imaging. Microchem. J. 114, 89-98.

Stephan, T., 2001. TOF-SIMS in cosmochemistry. Planet. Space Sci. 49 (9), 859-906.

Suh, H.S., Lee, J.S., Kim, P.S., Hwang, Y.H., Ryu, J.M., Chung, Y.H., 2012. Histopathological and ultramicroscopic changes induced by fluoride in soft tissue organs of the air-breathing teleost, Channa punctatus (bloch). Fluoride 45 (3 Pt 2), 263-273.

Sun, F., Li, C.B., Xiao, Y.H., Shi, J.Q., Gu, J., Xie, C., et al., 2011. Effects of fluorosis of coal burning on reproductive and endocrinology of male rats. Basic Clin. Med. 31 (10), 1077-1081.

Suzuki, K., Takii, T., Tomiyasu, B., Nihei, Y., 2006. Characterization of individual complex particles in urban atmospheric environment. Appl. Surf. Sci. 252 (19), 7022-7025.

Tang, X.Y., Zhang, Y.H., Shao, M., 2006. Atmospheric environmental chemistry. Advanced Educational Press, Beijing, pp. 268-274.

Tervahattu, H., Juhanoja, J., Kupiainen, K., 2002. Identification of an organic coating on marine aerosol particles by TOF-SIMS. J. Geophys. Res. Atmos. 107 (D16) ACH 18-1-ACH 18-7.

Tomiyasu, B., Suzuki, K., Gotoh, T., Owari, M., Nihei, Y., 2004. TOF-SIMS measurement for the complex particulate matter in urban air environment. Appl. Surf. Sci. 231, 515-519.

Wang, J., Wang, C., Chen, Z.L., 2011. Heavy metal pollution of $\mathrm{PM}_{10} / \mathrm{PM}_{2.5}$ near-surface in Guiyang. Environ. Sci. Technol. 34 (4), 74-76.

Wei, Y.X., Yang, W.F., Yin, Y., Rui, D.M., Hang, W.Q., Sun, J., et al., 2009. Pollution characteristics of Nanjing water-soluble ions in air fine particles under haze days. Environ. Sci. Technol. 32 (11), 66-71.

Wu, D., 2012. Hazy weather research in China in the last decade: A review. Acta Sci. Circumst. 32 (2), 257-269.

Wu, S.P., Yan, J.M., Zhang, M.M., Wang, X.H., Hong, H.S., Li, Z.Z., et al., 2009. UV-VIS and surfactant characteristics of water-soluble compounds in atmospheric aerosol. Chin. J. Process. Eng. 9 (Suppl.), 259-262.

$\mathrm{Xu}, \mathrm{B} . Y .$, 2006. Formaldehyde heterogeneous reaction in the atmosphere of the surface of the mineral oxide particles $\mathrm{PhD}$ Thesis Peking. U., Beijing, China.

Xu, L., Xie, M.X., 2013. Chronic fluorosis on the central nervous system. Chin. J. Pract. Nerv. Dis. 16 (4), 86.

Xu, G., Wang, J.M., Ma, S.H., Zhan, Y.Q., Ma, H.L., 2014. Effect of fluoride on the expression of ERK signaling pathway associated gene and proteins in the splenic lymphocytes of mouse. Acta Vet. Zootechnica. Sin. 45 (11), 1888-1894.

Yu, C.H., Zhou, Q., Li, Y.F., Zuo, Y.D., 2000. Analysis of poly aromatic hydrocarbon (PAHs) on individual particle from Beijing. Clean Coal Technol. 6 (4), 41-421. 
Yuan, C.S., Lin, H.Y., Chen, C.J., Chiang, S.W., Wang, J.L., 2009. Physicochemical properties and source apportionment of atmospheric aerosols sampled at roadside. China Powder Sci. Technol. (2), 1-6.

Zhou, Q., Li, J.Y., Liang, H.D., Wu, C.P., 2004. Recent developments on secondary ion mass spectrometry. J. Chin. Mass Spectrom. Soc. 25 (2), 113-120.

Zhou, Y., Zhang, H., He, J., Chen, X., Ding, Y., Wang, Y., Liu, X., 2013. Effects of sodium fluoride on reproductive function in female rats. Food Chem. Toxicol. 56, 297-303.
Zhu, Y.J., Olson, N., Beebe, T.P., 2001. Surface chemical characterization of $2.5-\mu \mathrm{m}$ particulates $\left(\mathrm{PM}_{2.5}\right)$ from air pollution in Salt Lake City using TOF-SIMS, XPS, and FTIR. Environ. Sci. Technol. 35 (15), 3113-3121.

Zhu, T., Shang, J., Zhao, D., 2010. The roles of heterogeneous chemical processes in the formation of an air pollution complex and gray haze. Sci. China: Chem. 54 (1), 145-153. 